\title{
CARTOGRAFIA COMO REFERENCIAL TEÓRICO-METODOLÓGICO PARA INVESTIGAÇÃO DE DOCUMENTOS EDUCACIONAIS
}

\author{
Rosanna Maria Araíjo Andrade Silva* \\ Carolina Rodrigues de Souza**
}

\begin{abstract}
RESUMO: No presente trabalho propomos um referencial teórico-metodológico orientado pelo conceito de cartografia. Este conceito foi desenvolvido por Gilles Deleuze e Félix Guattari em Mil Platôs. Pretendemos mostrar que o referencial pode ser utilizado para a investigação de documentos educacionais diversos, tais quais os materiais que Christian Laval analisou em A escola não é uma empresa. Mostraremos que tais documentos operam a partir de um princípio normativo denominado accountability, e que seu funcionamento é arborescente. Assim, é possível projetar seus decalques sobre um mapa, ou seja, é possível cartografar os documentos.
\end{abstract}

PALAVRAS-CHAVES: cartografia, documentos educacionais, accountability, escola neoliberal.

\section{CARTOGRAPHY AS A THEORETICAL-METHODOLOGICAL REFERENCE FOR THE INVESTIGATION OF EDUCATIONAL DOCUMENTS}

\begin{abstract}
In this study, we propose a theoretical-methodological reference guided by the concept of cartography. This concept was developed by Gilles Deleuze and Félix Guattari in Mille Plateaux. We intend to show that these references can be used for the investigation of various educational documents, such as the materials that Christian Laval analyzed in L'École n'est pas une entreprise. We will show that such documents operate from a normative principle called accountability, and that their functioning is arborescent. Thus, it is possible to project their decals on a map, that is, it is possible to cartograph the documents. The documents' arborescent characteristics make their projection on a map possible, that is, it makes cartography possible.
\end{abstract}

KEYWORDS: cartography, educational documents, accountability, neoliberal school.

\footnotetext{
* Licenciada em Ciências Exatas pela Universidade de São Paulo, mestranda em Educação na Universidade Federal de São Carlos. Email: rosanna.silva@alumni.usp.br; Orcid: https://orcid.org/0000-0001-7624-355X

** Doutora em Educação pela Universidade Federal de São Carlos, com co-tutela na École Normale Supérieure de Cachan. Docente na Universidade Federal de São Carlos, no Departamento de Metodologia de Ensino. Email: carolinasouza@ufscar.br; Orcid: https://orcid.org/0000-0002-7826-1011
} 


\section{Introdução}

No presente artigo, apresentaremos uma proposta teórico-metodológica para investigação de documentos educacionais inspirada pelas reflexões de Christian Laval e Gilles Deleuze (incluindo seus trabalhos com Guattari). Em Mil platôs o empreendimento da cartografia realizado por Deleuze e Guattari levou-os a descrever o capitalismo como uma axiomática, constituindo uma lógica representativa dos decalques. De forma semelhante, Christian Laval, em $A$ escola não é uma empresa: o neoliberalismo em ataque ao ensino público, investiga a lógica neoliberal que permeia a educação mundial. O sociólogo identifica uma articulação complexa entre organismos internacionais e administrações locais; sua análise do quadro mundial da educação serve do caso francês para orientar a análise. Laval se utiliza de uma diversidade de documentos para realizar tal análise, comparando com outros contextos e apontando para uma presença internacional do que o autor chama de escola neoliberal. Pretende-se, no seguinte trabalho, mostrar como é possível realizar uma análise de documentos educacionais diversos, traçando sua lógica neoliberal, a partir do conceito de cartografia elaborado por Deleuze e Guattari. As análises dos autores, apesar de serem orientadas por uma perspectiva diferente da de Christian Laval, colocam como programa intelectual a necessidade de uma ruptura com a doxa. Os autores, por caminhos diferentes, analisam o capitalismo como uma lógica global. O primeiro capítulo de Mil platôs começa com uma pequena introdução da qual se segue seis princípios. Logo no início é apresentada a contraposição que se propaga por todo o texto, entre rizoma e árvore. Depois, aproximando-se do final do texto, os autores relacionam a estes conceitos, respectivamente, o mapa e o decalque, o que é feito na sessão relativa ao quinto e sexto princípios. Nessa sessão, a partir dos matemáticos Pierre Rosentiehl e Jean Petitot, os autores apresentam uma descrição da árvore como sistemas que se hierarquizam em torno de um centro. Segundo os autores, os sistemas arborescentes dominaram a realidade ocidental, sendo assim, é necessário levá-los em consideração. Se uma forte crítica é realizada por Deleuze e Guattari aos sistemas arborescentes, nem por isso eles deixam de apresentar formas e recomendações para estudá-los. Assim, pretende-se mostrar, inspirado no diagnóstico global da educação apresentado por Christian Laval e a partir das reflexões apresentadas sobre o capitalismo por Deleuze e Guattari, como é possível realizar uma cartografia de documentos, evidenciando um princípio axiomático que está no âmago das práticas neoliberais: a accountability.

\section{Documentos educacionais e accountability}

Em A escola não é uma empresa: o neoliberalismo em ataque ao ensino público, Laval (2020) investiga um determinado modelo de educação, que passa a se tornar hegemônico a partir dos anos 1980. A construção deste modelo é apresentado como um processo difuso executado nas últimas décadas por variadas instâncias nacionais e internacionais. A constatação da existência de um modelo decorre de um determinado olhar analítico apresentado por Laval pois, segundo o autor, determinadas medidas que 
afetam os sistemas escolares poderiam, a princípio, ser vistas como isoladas umas das outras. A relação entre elas é, a depender do recorte adotado pelo pesquisador, pouco visível. Mas, quando analisadas em conjunto, elas adquirem outro significado. Tomando como base documentos sobre educação elaborados por agências internacionais ${ }^{1}$, bem como relatórios governamentais oficiais e artigos especializados, é possível evidenciar a lógica a qual respondem dispositivos e instituições educacionais. O autor revela um "quadro mundial de políticas educacionais", que opera como o único discurso legítimo sobre a escola, e que teria alcance e potencial de transformação dos sistemas escolares a nível global (LAVAL, 2020, p. 819).

Para compreender a totalidade desses fenômenos, Laval mobiliza a noção de fato social total de Marcel Mauss, o que permite posicionar-se contra "certa tendência hiperempiricista", na qual os pesquisadores realizam "análises empíricas pontuais em campos muito específicos, ou microcampos" (LAVAL, 2020, p. 8). A noção de fato social total possibilita o analista atravessar uma série de domínios da vida social aparentemente desconectados para chegar a uma totalidade social ${ }^{2}$. O que possibilita pensar em uma totalidade analítica que dá conta do conjunto de medidas nos sistemas escolares é a categoria de escola neoliberal. De certa forma, trata-se de um processo de associação que vai seguindo os fenômenos que atravessam essa categoria. O que é feito através da associação de uma “"literatura cinzenta' composta de centenas de relatórios oficiais e artigos especializados, à abundante produção das organizações internacionais, 'guardiãs da ortodoxia”' (LAVAL, 2020, p. 19). A tradição sociológica mobilizada por Laval segue uma orientação teórico-metodológica, apontada primeiramente por Max Weber, que apresenta a pesquisa como um questionamento da "ortodoxia existente em certo momento no campo científico", a realização de uma "refutação da opinião dominante (doxa)" (LAVAL, 2020, p. 8-9).

Nesse ponto há uma convergência entre Laval e Deleuze no que se refere à opinião (doxa). Deleuze, desde seus trabalhos iniciais até os da maturidade, sempre foi um crítico da opinião. No primeiro capítulo de Diferença e repetição o bom-senso e o senso comum são apresentados como as duas metades da doxa; ambas se conjugam para realizar uma distribuição sedentária. No sistema aberto apresentado por este livro a distribuição sedentária realiza o trabalho da representação, contra o qual a lógica paradoxal de Deleuze se insurge, através de uma contraposta distribuição nômade (DELEUZE, 2018, p. 63-64). Em O que é a filosofia?, escrito em um momento de maturidade, o problema da opinião reaparece. Mas dessa vez a partir da discussão dos modos de criação próprios à filosofia, à ciência e à arte, a dizer, respectivamente: os conceitos, às funções/proposições e aos afectos/perceptos. A partir de suas respectivas criações, cada uma delas traz algo do caos, rompendo os limites da opinião.

\footnotetext{
1 Alguns exemplos de organizações citadas por Laval (2020) são a Organização Mundial do Comércio (OMC), Organização para Cooperação e Desenvolvimento Econômico (OCDE), Banco Mundial, Fundo Monetário Internacional (FMI) e Comissão Europeia. Em adição a esta lista, destacamos também o papel da Organização das Nações Unidas para a Educação, a Ciência e da Cultura (UNESCO) e do Banco Interamericano de Desenvolvimento (BID).

${ }^{2}$ A noção de totalidade pode parecer avessa à filosofia de Deleuze e Guattari, mas, no caso da proposta do presente trabalho, pode-se pensar num sentido de mundialização associado a uma pretensão de totalidade.
} 
No modelo hegemônico de educação descrito por Laval, tratado por seus proponentes como expressão pura de um senso comum e um bom-senso educacionais, a escola deve se organizar a partir dos mesmos princípios de uma empresa. A eficiência, definida como uma grandeza mensurável, é o valor que fundamenta o funcionamento da instituição, que deve se orientar para a redução de custos e maximização dos resultados. A avaliação da escola torna-se uma operação indispensável, que permite a reorientação das práticas em função das metas pré-determinadas ${ }^{3}$. A ação pedagógica é traduzida em termos de resultados quantificáveis, e estes são tomados como indicadores da qualidade da instituição. $\mathrm{O}$ autor aponta que organismos internacionais, em conjunto com administrações locais, desenvolveram critérios de qualidade padronizados, possibilitando a comparação entre sistemas escolares a nível global (LAVAL, 2020, p. 37, 210).

A temática da eficiência entrelaça-se com a da democratização da escola: qualquer organização que provê serviços à população é supostamente responsável por apresentar resultados, isto é, produzir dados a respeito de seu funcionamento que demonstrem que a aplicação dos recursos recebidos é eficiente (LAVAL, 2020, p. 209-211). Esta noção é sintetizada pelo conceito de accountability ${ }^{4}$. Segundo a definição do sociólogo português Almerindo Afonso a accountability apresenta três dimensões: avaliação, prestação de contas e responsabilização. O pilar da avaliação é entendido como um processo de obtenção, tratamento e análise de informações fundamentadas teórica e metodologicamente, a partir das quais seria possível produzir juízos de valor sobre uma dada realidade social. A prestação de contas condensa duas etapas: a de fornecer informações e produzir justificações (ou argumentações) da maneira mais objetiva possível. A dimensão da prestação de contas estaria fundamentada no direito democrático à informação. Por fim, o terceiro pilar estruturante da accountability é o da responsabilização. Esta dimensão sintetiza mecanismos de imposição, coação ou sanção, que podem ser sanções negativas (ou simplesmente punições) ou o que o autor denomina "formas legítimas de indução de responsabilização", como atribuição de recompensas materiais ou simbólicas, reconhecimento informal do mérito e assunção autônoma de responsabilidade. Os elementos de responsabilização são aqueles que permitem premiar o bom e punir o mau comportamento. Para o autor, procedimentos que dizem respeito a apenas algumas dimensões da prestação de contas ou da responsabilização podem ser designados como formas parcelares de accountability.

O estabelecimento de "fatos autênticos" a partir dos quais as instituições são avaliadas, e a publicização dos dados coletados, são considerados como requisitos para que as instituições se guiem por valores como responsabilidade e transparência, e seriam pressupostos para a participação da sociedade em uma democracia substantiva. Afonso associa a temática da accountability a "demandas por maior participação e transparência” em esferas democráticas, mas também considera que a defesa deste

\footnotetext{
${ }^{3}$ Pode-se interpretar a submissão de ações a metas pré-estabelecidas a partir da ideia de Mil Platôs (2011) de movimento centrípeto.

${ }^{4}$ Não existe um termo único em português que traduza o conceito de accountability (AFONSO, 2010). Por isso, optamos por manter a grafia do termo em inglês.
} 
princípio pode se dar por razões instrumentais ou de controle (AFONSO, 2010, p. 148-152). Laval (2020, p. 253-255), por sua vez, alerta que a descentralização (a transferência de responsabilidades para as diretorias de ensino e para os estabelecimentos escolares no sistema francês) foi defendida como uma medida democrática, capaz de aproximar o cidadão comum das esferas de decisão. Entretanto, esta desconcentração de poder apenas foi tolerada na medida em que os níveis intermediários da administração estivessem comprometidos com o ideal da eficiência econômica. O referencial cartográfico permite analisar estas dinâmicas de centralização/descentralização em dois níveis distintos: as pretensões em submeter os sistemas escolares à lógica neoliberal correspondem a uma análise no nível global; já o impacto dos mecanismos e dispositivos que operam segundo essa lógica nas comunidades escolares ${ }^{5}$ e nas subjetividades corresponde a uma análise no nível local.

\section{O conceito de cartografia em Mil Platôs}

No primeiro capítulo de Mil platôs: capitalismo e esquizofrenia os autores apresentam o conceito de cartografia ${ }^{6}$ É possível localizar referências à cartografia como dispositivo aplicado em contexto clínico, na perspectiva da equizoanálise (MIGUEL, 2015; PELBART, 2016). Esse conceito é também é frequentemente utilizado nas ciências humanas como metodologia para pesquisas de campo (ALBUQUERQUE; HENNIGEN; FONSECA, 2018; CORRÊA; BRITO, 2015; KASTRUP, 2007; OLIVEIRA; PARAÍSO, 2012; PASSOS; BARROS, 2009). Utilizaremos aqui uma interpretação do conceito de cartografia inspirada na leitura do próprio texto de Deleuze e Guattari, para além dos distintos propósitos e perspectivas presentes nestes últimos trabalhos. Pretendemos examinar a possibilidade de investigar documentos educacionais através do conceito de cartografia, utilizando-o como uma ferramenta de análise crítica que não pressupõe um caminho pré-determinado para a investigação, e assim permite estabelecer conexões entre conceitos e mesmo entre diferentes campos do conhecimento.

No primeiro capítulo de Mil Platôs os autores apresentam uma repartição ${ }^{7}$ - rizoma e árvore - a qual corresponde outra - mapa e decalque. A árvore pressupõe uma "forte unidade principal", um eixo central (sua raiz) que organiza e ordena as multiplicidades, capturando-as em uma estrutura, em um movimento centrípeto. O rizoma, por outro lado, é um "sistema acentrado não hierárquico", no qual a

\footnotetext{
${ }^{5}$ Também é possível mapear as estratégias de resistência a estes mesmos mecanismos.

${ }^{6}$ Fernand Deligny, em seu trabalho de educador com crianças autistas, desenvolve o conceito de mapa entre 1969 e 1970. Os mapas são traçados dos movimentos das crianças, de seu agir. O método cartográfico de Deligny "não se trata de interpretar o comportamento das crianças, mas de identificar/localizar espacialmente [...] os movimentos delas” (MIGUEL, 2015, p. 58). Deleuze e Guattari citam Deligny no primeiro capítulo de Mil Platôs; o quinto e o sexto princípios do rizoma foram inspirados em seu conceito de cartografia. Convém destacar que os conceitos de cartografia de Deligny e de Mil Platôs são homônimos, porém distintos.

${ }^{7}$ Embora essa divisão pareça apresentar dois modelos em um dualismo, os autores alertam que não é disto que se trata. Servir-se desta formulação é apenas parte de um processo. A partir desta passagem operam-se deslocamentos, movimento que permite por sua vez desfazer todos os dualismos, alcançando assim "um processo que recusa todo modelo". Portanto, não se trata de dois modelos, mas da árvore como modelo e do rizoma como anti-modelo (DELEUZE; GUATTARI, 2011, p. 42)
} 
circulação de estados se dá sem caminhos preferenciais ou pré-determinados. O rizoma pode ser mapeado (ou cartografado): o mapa "é aberto, conectável em todas suas dimensões, desmontável, reversível, suscetível de receber modificações constantemente [...] [e de] adaptar-se a montagens de qualquer natureza". Já o decalque implica a lógica da árvore, que é a da reprodução: "a árvore articula e hierarquiza os decalques, que são como as folhas da árvore”. O decalque remete o mapa a um modelo, isolando "o que ele tem a intenção de reproduzir, com a ajuda de [...] procedimentos de coação", propagando assim redundâncias ao infinito (DELEUZE; GUATTARI, 2011, p. 20-21, 29-33, 43).

Os movimentos de centralização e descentralização abordados no primeiro capítulo de Mil platôs formam uma dinâmica que continua funcionando o livro inteiro. Como fica claro na conclusão, através da operação da máquina abstrata que arrasta os agenciamentos maquínicos entre dois planos: 1) de organização (relativo aos movimentos de centralização, ou seja, à árvore); 2) de composição (relativo aos movimentos de descentralização, ou seja, ao rizoma) (DELEUZE; GUATTARI, 2012, p. 230-246).

No primeiro capítulo os movimentos são apresentados a partir de temas da biologia (a contraposição entre o rizoma com seus bulbos e a árvore com suas raízes). Mas os autores passam por uma diversidade de temas, para enumerar alguns: psicanálise, história natural, linguística, questões de grupos políticos minoritários, filosofia (desde os gregos até os contemporâneos aos autores), ciências (desde a ciência e a matemática grega até os contemporâneos). O livro apresenta um verdadeiro sobrevoo, atravessado por uma lógica rigorosa ${ }^{8}$, através de uma diversidade de temas. O último capítulo do livro se debruça em uma contraposição conceitual que também é interessante para pensar o tema da accountability; os conceitos também exprimem movimentos de centralização e descentralização, respectivamente: o estriado e o liso.

O capítulo 14, denominado O liso e o estriado por si só é paradigmático do caráter transversal em relação aos temas; os autores vão realizando uma operação de seleção dos materiais empíricos relativos a cada um desses temas a partir do critério de seleção da máquina abstrata responsável por direcionar os fenômenos para o centro (estriamento) ou para o fora (alisamento). A partir da oposição de direito entre os espaços liso e estriado, suas variações e relações (as misturas de fato), os autores discutem os conceitos de liso e estriado passando por diversos modelos, cada um deles marcado também por uma oposição. Os temas pelos quais o capítulo passa são: 1) Modelo tecnológico (têxtil), no qual o tecido é apresentado como um espaço estriado (consiste de dois conjuntos paralelos de fios - um fixo e um móvel - que se cruzam; um dos lados do tecido é delimitado pelo quadro da urdidura; sendo portanto um espaço finito), em oposição ao feltro (um emaranhado de fibras, sem centro, sem lado direito e avesso, que pode aumentar em qualquer direção); 2) Modelo musical, que se serve da distinção desenvolvida por Pierre Boulez entre espaço-tempo liso e espaço-tempo estriado no âmbito musical; neste modelo a diferença

\footnotetext{
8 Para o comentador David Lapoujade (2015, p.13) a filosofia de Deleuze se apresenta como "uma lógica irracional dos movimentos aberrantes [...] que, em determinadas condições constituem a mais alta potência de existir, enquanto que as lógicas irracionais constituem a mais alta potência de pensar".
} 
entre o liso e o estriado é sensível; 3) Modelo marítimo, no qual o mar é apresentado como "o espaço liso por excelência" (DELEUZE, GUATTARI, 2012, p. 198), mas que foi estriado a partir de latitudes e longitudes; no espaço estriado o trajeto é subordinado aos pontos, no espaço liso, inversamente, os pontos são subordinados ao trajeto; 4) Modelo matemático, no qual a oposição se dá entre multiplicidades métricas (extensivas) e não métricas (intensivas); 5) Modelo físico, no qual se desenvolve o conceito físico-social de trabalho, que opera uma estriagem do espaço, enquanto a circulação do capital em um capitalismo mundial integrador recria um espaço liso; 6) Modelo estético, em que se diferenciam o espaço óptico (de visão distanciada) e o espaço háptico (de visão aproximada) (DELEUZE; GUATTARI, 2012, p. 191-228).

Deleuze e Guattari apresentam proximidades e distâncias em relação ao liso e ao estriado. Assim como os autores, que a partir da distinção traçada entre o liso e o estriado identificam, em cada exemplo, a proximidade com cada um dos polos abstratos (e a dinâmica de variação destas distâncias), podemos proceder da mesma forma com os documentos, pois estes são fenômenos derivados dos sistemas burocráticos da axiomática capitalista.

\section{Cartografar os decalques}

Nas sessões anteriores argumentamos que diversos documentos educacionais produzidos a partir das últimas décadas do século XX, especialmente aqueles elaborados por Estados e organismos internacionais, operam a partir de um princípio axiomático: a accountability. Veremos que as raízes deste conceito já são indicativas que a accountability é um princípio que se traduz em uma lógica arborescente.

Para isso recorreremos a um artigo da antropóloga britânica Marilyn Strathern, cujo título é From improvement to enhancement: an anthropological comment on the audit culture. Nele, a autora analisa o fenômeno da chamada "audit culture" ("cultura de auditoria") na Universidade de Cambridge durante a década de 1990; a autora investiga o fenômeno a partir do contexto local, procedimento característico de sua abordagem metodológica. Além disto, a antropóloga afirma também que a cultura de auditoria é um fenômeno de proporções globais.

Para Strathern (1996/7) a auditoria (uma prática contábil) e a avaliação (uma prática característica de instituições acadêmicas) são ferramentas onipresentes da accountability. A antropóloga considera que o movimento de influência mútua entre a educação e o mundo comercial que culmina na ideia de accountability é um exemplo de replicação cultural. Este conceito pode ser entendido como um movimento circular: começa com a transferência de valores de um domínio da vida cultural até outro; então, com sua forma original alterada, eles retornam ao primeiro domínio. O mundo da educação contribuiu para a constituição da accountability com a ideia de mensuração da performance humana, ou seja, com a avaliação (entendida como um exame das habilidades do estudante na forma de um teste escrito, que resulta em 
uma nota, ou seja, um sumário numérico do rendimento). Já o mundo dos negócios contribuiu com a ideia de auditoria e de balanços contábeis como instrumentos de mensuração da eficiência de uma empresa. A accountability nas universidades é resultado da transferência de valores típicos das instituições acadêmicas para as empresas; após a incorporação e transformação destes valores, são as empresas que passam a influenciar o mundo da educação.

Considerando que o fenômeno da accountability surgiu da influência entre os mundos do comércio e da educação (STRATHERN, 1996/7, p. 4), e tendo em vista que os procedimentos característicos do comércio envolvem práticas contábeis, enquanto os da educação formal envolvem práticas burocráticas, pode-se relacionar o fenômeno com aquilo que Deleuze e Guattari chamam de decalques. Segundo os franceses a contabilidade e a burocracia operam por decalques (DELEUZE; GUATTARI, 2011, p. 33). Da mesma forma pode-se aplicar esse conceito às operações dos documentos educacionais oficiais ${ }^{9}$. A política de accountability implementada pelos Estados, em conformidade com as recomendações produzidas por organizações transnacionais, pode ser compreendida como uma unidade central que institui um modelo para os sistemas escolares, isolando os aspectos a serem reproduzidos e articulando as ações que conduzem a esta finalidade; a accountability tem, portanto, as características da árvore. Os mecanismos de avaliação e gestão educacional definidos por este paradigma "enraízam unificações e totalizações, massificações, mecanismos miméticos". Podemos pensar que os documentos operam como decalques, pois reproduzem "algo se dá já feito, a partir de uma estrutura que sobrecodifica ou de um eixo que suporta” (DELEUZE; GUATTARI, 2011, p. 30-31).

Para Deleuze e Guattari “é preciso sempre projetar o decalque sobre o mapa” e "esta é uma questão de método". O rizoma e o mapa têm múltiplas entradas; sendo assim pode-se "entrar nelas pelo caminho dos decalques" (DELEUZE; GUATTARI, 2011, p. 31-33). Realizar uma cartografia de documentos educacionais é possível ao projetarmos seus decalques sobre um mapa, ou seja, ao percorrer seus mecanismos de organização, estruturação, reprodução e impasses, tornar visíveis redundâncias e rupturas, estabelecendo novas conexões. Pode-se utilizar o referencial cartográfico para evidenciar as pretensões dos documentos de constituírem processos arborescentes assim como seu processo de espalhamento. Se por um lado a lógica neoliberal articula as multiplicidades escolares em torno da unidade de seu modelo, por outro lado essa lógica opera uma flexibilização (quando comparada à burocracia e ao taylorismo ${ }^{10}$ ) em nome da proliferação de suas práticas. Esta dinâmica, por exemplo, pode ser pensada em termos de estriamento e alisamento. Além disso, a partir do referencial cartográfico é possível evidenciar linhas de fuga, ou seja, apontar rupturas na lógica estratificada da que permeia o documento. Pode-se dizer que isso implica uma constituição de um mapa pelo pesquisador a partir dos decalques, evidenciando os agenciamentos do documento que oscilam entre movimentos centrípetos e centrífugos.

\footnotetext{
${ }^{9}$ Documentos não oficiais (como artigos, relatórios de pesquisa ou mesmo entrevistas com autoridades encarregadas da gestão educacional) também podem ser incluídos na análise que se segue.

${ }^{10}$ Esta transformação no funcionamento das instituições escolares e universitárias no final do século XX é discutida por Laval (2020) no primeiro capítulo de A escola não é uma empresa: o neoliberalismo em ataque ao ensino público.
} 
Tornar visíveis os mecanismos de redundância e as rupturas dos documentos é um exercício de "produzir hastes e filamentos [...] que se conectam com elas [as raízes] penetrando no tronco, podendo fazê-las servir a novos e estranhos usos” (DELEUZE; GUATTARI, 2011, p. 34).

\section{REFERÊNCIAS}

AFONSO, Almerindo. Um olhar sociológico em torno da accountability em educação. In: Esteban, Maria Teresa; Afonso, Almerindo (Orgs.). Olhares e interfaces: reflexões críticas sobre a avaliação. São Paulo: Cortez, p. 147-170, 2010.

ALBUQUERQUE, Alana; HENNIGEN, Inês; FONSECA, Tania. Cartografias no ciberespaço: experimentações metodológicas em espaços híbridos. Psicologia \& Sociedade, v. 30, e174086, 2018.

CORRÊA, Edilena; BRITO, Maria. Experimentações rizomáticas no currículo de ciências: pelas vias da diferença. Linha Mestra, v. 27, p. 79-81, 2015.

DELEUZE, Gilles. Diferença e Repetição. Trad. Luiz Orlandi. 1 ed. Rio de Janeiro/São Paulo: Paz e Terra, 2018.

DELEUZE, Gilles; GUATTARI, Félix. O que é a filosofia? Trad. Bento Prado Jr. e Alberto Alonso Muñoz. 3 ed. São Paulo: Editora 34, 2010.

DELEUZE, Gilles; GUATTARI, Félix. Mil Platôs. Trad. Ana Lúcia de Oliveira, Aurélio Guerra Neto e Célia Pinto Costa. Vol. 1. 2 ed. São Paulo: Editora 34, 2011.

DELEUZE, Gilles; GUATTARI, Félix. Mil Platôs. Trad. Peter Pál Pelbart e Janice Caiafa. Vol 5. 2 ed. São Paulo: Editora 24, 2012.

KASTRUP, Virgínia. O funcionamento da atenção no trabalho do cartógrafo. Psicologia \& Sociedade, v. 19(1), p. 15-22, 2007.

LAPOUJADE, David. Deleuze, os Movimentos Aberrantes. Trad. Laymert Garcia dos Santos. 1 ed. São Paulo: n-1 edições, 2015.

LAVAL, Christian. A escola não é uma empresa: o neoliberalismo em ataque ao ensino público. Trad. Mariana Echalar. 2 ed. 1 reimpressão. São Paulo: Boitempo, 2020.

MIGUEL, Marlon. Guerrilha e resistência em Cévennes. A cartografia de Fernand Deligny e a busca por novas semióticas deleuzo-guattarianas. Revista Trágica: estudos de filosofia da imanência, v. 8, n. 1, p. 5571, 2015. 
OLIVEIRA, Thiago; PARAÍSO, Marlucy. Mapas, dança, desenhos e a cartografia como método de pesquisa em educação. Pro-posições, v. 23, p. 159-178, 2012.

PASSOS, Eduardo; BARROS, Regina. A cartografia como método de pesquisa-intervenção. In: Passos, Eduardo; Kastrup, Virgínia; Escóssia, Liliana. (Org.) Pistas do método da cartografia: pesquisa-intervenção e produção de subjetividade. 1 ed. Porto Alegre: Sulina, p. 17-31, 2009.

PELBART, Peter. Linhas erráticas. In: $O$ avesso do niilismo: cartografias do esgotamento. 2 ed. São Paulo, n-1 edições, p. 299-333, 2016.

STRATHERN, Marilyn. From improvement to enhancement: an anthropological comment on the audit culture. In: The Cambridge Journal of Anthropology, n. 3, v. 19, p. 1-21, 1996/7. 